\title{
THE PROGRESS OF ASYMMETRIES IN AXEL HONNETH'S RECOGNITION THEORY
}

\author{
Roland Theuas DS. Pada \\ University of Santo Tomas, Philippines
}

\begin{abstract}
I aim to articulate and develop a consolidated model of Axel Honneth's Recognition Theory. This paper aims at investigating the relationship of asymmetries of identities and social struggles as a progressive process of recognition in Honneth's works. My paper is divided into three parts. The first part provides a consolidated outlook on Honneth's Recognition Theory from the Struggle for Recognition to his more recent work Freedom's Right. The second part covers the relationship between social struggles, social solidarity, and their effects on regenerating the necessary normative resources for individual selfactualization. The last part is my take on Honneth's Recognition Theory in the form of understanding social pathologies in the context of investigating deficits of normative resources for self-actualization.
\end{abstract}

Keywords: Recognition Theory, reconstructive normative simulations, social pathologies, Critical Theory

\section{INTRODUCTION}

If there would be an apt analogy for describing recognition theory, it would be through the philosophical discussion of meaning and context. The function of meaning always relies on the already existing sets of relations each responsible for preserving, reproducing, and altering the context of meaning. The trajectory of recognition theory, likewise, follows the same path. Recognition theory depicts the working process of mutual acknowledgment of identities as a product of existing social norms. Recognition, like the problem of meaning, is rife with impasses that prevent the mutual acknowledgment of identities. In this regard, movements for social struggle acts as an intermediary to raise claims that are withheld from individuals or groups that invoke already existing normative claims.

Identities, despite their diversity, are always formed within existing social practices. Struggles for recognition offer a workable negotiation of aligning norms to acknowledge existing norms and integrate individual identities. The tension that recognition theory tries to resolve is the asymmetrical relations of identities with existing social norms. The advantage of this theory is that it neither invokes nor appeal to transcendental, fixed, or universal values that come from without or from some 
imaginary form of social ordering reminiscent of Plato's Noble Lie (2003, 107). Honneth's recognition theory is an innovative appropriation of Hegel's Philosophy of Right coupled with the socialized philosophical anthropology of G.H. Mead and Emile Durkheim. Honneth's theoretical inspiration comes from Hegel's comprehensive account of socialized identity formation from the constant learning process offered by dialectical engagements. These social interactions are a mutual and reciprocal process that undergirds the reproduction of norms, as well as the creation of new norms to adapt to new identities in society. The beauty of Honneth's theoretical model of recognition is that it serves as a description of society based on the normative expectations of subjects and their struggle to affirm their unique identities. This model not only overcomes the difficulty of going through the problem of searching for an originary source of norms, but it also overcomes the problem of mediating transcendental and immanent sources of norms. With this in mind, Honneth's critical approach to social philosophy is derived from the characteristic of describing the normative expectations of individuals as both the immanent and transcendent source of resolving and mediating claims for recognition. Honneth's social philosophy is based on the following premises: (1) that identity is learned through constant social interactions, and it is not derived from without, but from the already existing (See Honneth 2014); (2) That individuals are needy subjects, requiring the affirmation of others (Honneth 1995, 148); (3) the teleological trajectory of Honneth's critical theory is social solidarity (Honneth 1995, 178). Societies may change whichever norms it practices for the sake of maintaining the reciprocal economy of recognition, but they are only doing this for the sake of maintaining social solidarity; (4) the last premise is that social struggles are based on normative claims that already exist and are in practice (Honneth 2014, 818).

\section{HONNETH'S RECOGNITION THEORY}

What Honneth offers in his theoretical approach is a way of looking at the motivations of social struggles from their inherent claim and finding explanations for the normative resource that was withheld from them. In his reading of Hegel, Honneth notes that crime is committed in the context that a subject is aware that he or she is breaking away from normative conditions that would otherwise be considered as an established 'universal recognition of the injured party. Moreover, breaking away from the norm also implies that the subject is cognizant of the fact that he or she is no longer acknowledged by the legal norms as a person worthy of recognition (Honneth 1995, 53). For either a good reason or a bad reason, the criminal is engaged in an asymmetrical relationship with society as he or she tries to attempt to convince society of the validity of their self-actualization. Another example that could be raised in this case is Honneth's investigation of the LGBT community's claim for the legitimacy of same-sex marriage. Today's acceptance of homosexual marriage has been a product of a prolonged struggle for the recognition that lesbian or gay couples are just as capable of love or intimacy towards each other and their children. Thus, the norm and legal status for marriage are transformed through this struggle, Honneth $(2014,150)$ further notes: 
The legal solution that has been implemented in order to remove this inequality by granting a weak legal status to 'non-married' life partners can only be regarded as temporary. In the long term, the source of the reasons used to justify excluding homosexual couples from the legal privileges of officially sanctioned marriage will dry up, leaving only the option of abolishing marriage completely or granting every kind of intimate life partnership the official right to marry. In the first case, the legal consequences of marriage would only take effect once the couple decided to form a family, leaving childless couples to arrange their future financial support in the form of private contracts. In the second case, all couples, regardless of their sexual orientation, would have the legal option of 'officially' registering their relationship and thus enjoying the corresponding legal rights and obligations.

By looking at this example, we can see that the transformation of normative practice is attainable via an appeal to existing normative practices. In other words, the initial asymmetrical relationship between the legal norm of marriage and the struggle for recognition by the LGBT community shows a progressive learning instance in the transformation of norms. Despite society's tendency to affirm a symmetrical universalized normativity, asymmetries in identities and normative claims help reinforce and adapt existing normative principles to new social circumstances. While it is easy to hastily generalize Honneth's social philosophy as an optimistic outlook on society or, as Christopher Zurn $(2015,193)$ puts it, "Pollyannaish," it must be noted that learning instance in any struggle for recognition is the only possible positive outcome in any social conflict. This issue was mentioned in Ricoeur's reading of Hegel and Honneth's choice of words in expressing recognition as a product of a "struggle," which Ricoeur thinks could be expressed in a "more peaceful experiences of recognition" (Ricoeur 2005, 186). While at this point, Honneth's language may not ring too optimistic nor "Pollyannaish," Honneth's insistence on the use of struggle or Kampf emphasizes the societal investment that is behind every normative principle advanced by recognition. In an interview with Gonçalo Marcelo, Honneth was asked if it was possible to have a society where recognition is possible without disrespect. Honneth $(2013,217)$ replies:

I would say no. But I have a much more positive conception of struggle. When I was reading Ricoeur, I was surprised that he seemed to take struggle as being something very close to war. The opposition he's working with is war and peace. This is not how I am thinking. You see, I take struggle as being an enormously productive force in our human lifeworld. And it takes thousands of forms. It starts with the young baby, who is struggling against his or her parents. It's what's happening in classrooms in different forms. It slowly changes the way we understand the principles of recognition, the way we understand ourselves, and it slowly helps to make our societies normatively better. So the first 
difference is that I have a productive, positive understanding of struggle. I'm more interested in the small, everyday forms of struggle and not in the big struggles, which are, I think, what Ricoeur has in mind. The second aspect to which I am opposed is that what he describes as 'bad infinity' I would describe as productive infinity.

While the choice of the word "struggle" or "Kampf" might disturb Ricoeur's aesthetic sensibilities, it is notable that Honneth's Hegelian influence resonates with the productive possibilities of social struggles in constantly transforming encounters between heteronomous identities. It is through this heteronomy where society can enlarge its normative resources by opening variations in the possibilities where individuals can attain self-realization. Bolaños $(2016,112)$ further adds that Ricoeur's attempt to depoliticize recognition in the form of peaceful means is somewhat naïve and idealistic in terms of resolving actual social conflicts or normative disputes. Moreover, by focusing on the aesthetic sensibility of violence in the context of an allout life or death struggle, without understanding Hegel and Honneth's nuanced metaphors for consciousness can somewhat avert the attention of readers to Honneth's productive understanding of surpluses in normative resources.

Suffice it to say that Honneth's anticipation of the asymmetrical nature of recognition in social interactions intends to look at the tension between existing normative values as they are challenged from normative claims of new identities. While the conflict might seem exhausting, demanding, and never-ending, there is a benefit of looking at these instances as a possible avenue for progress. The tension experienced in this process of recognition could be likened to paradigm shifts in science espoused by Kuhn's The Structure of Scientific Revolution. For example, a shift in the perspective of viewing Uranus changed its status from a comet to a planet (1962, 116-117). Likewise, changes in the normative perspectives of both the individual, state, and society as a whole occur when different perspectives are introduced. Much as Herschel's observations were scoffed at by his peers or people like Ignaz Semmelweis was laughed at and ridiculed for his hygiene prescriptions in the medical profession (Wyklicky, et al., 1983, 368), their normative claims in the field of science had to undergo the process of convincing and demonstrating that the existing scientific normative claim requires modification. The process of changing or modifying societal norms also requires effort, or as Honneth aptly puts it, struggle. What is interesting in the development of Honneth's recent works is the historical reconstructions that he offers that are products of social struggles for recognizing norms that run contrary to existing societal norms. From the changes in the structure of friendship as a modern development that is no longer limited to class or even sexual orientation (Honneth 2014, 138 -141) to the transformation of wage labor to socialized labor (Honneth 2014, 238-240), shows that societal norms evolve to accommodate new identities and preserve existing ones by appealing to shared values and visions of self-actualization. In hindsight, one can say that yesterday's radicalism is today's conservative and that today's radicalism is tomorrow's conservative. These progressive movements show that the possibilities for social transformation will last as long as humans live to interact and fulfill their never-ending neediness for societal 
validation or recognition. While socialist movements might look revolutionary and ground-breaking in their time several decades ago, today, forms of conservatism are often frowned upon and viewed as anti-progressive. Thomas Sowell, an African American economist, and social philosopher, for example, laments the state of leftist ideology and the social justice movement:

What "social justice" seeks to do is eliminate undeserved disadvantages for selected groups... this is often done in disregard of the costs of this to other individuals or groups - or even the requirements of society as a whole. (Sowell 1999, 9)

What seemed to be a proclamation that would have been popular in the time where the norms of conservatism were popular, today's political climate in the United States would find Sowell's social criticism as distasteful. Sowell's critical views on social justice do emphasize the dialectical engagement that is occurring in the United States as another instance in history where the cycle between radicalism and conservatism produces societal norms. As much as Sowell's satire of leftist ideology in Grasshopper and Ant shows the need to revive old economic values instead of social justice's indulgence in gratifying ideological persuasions at the cost of economic distress (See Sowell 2011). In the same manner, like Jonathan Swift's $A$ Modest Proposal's suggestion to sell Irish children for food and economic upliftment of the Irish (2008, 5-12), satirical critiques show the asymmetrical relationship in the changes of normative expectations and their desire to re-align norms to asymmetrical societal expectation.

Honneth $(1995,129)$ stipulates that the need for symmetrical social solidarity remains as a societal goal in as much as societal values may conflict or differ in the horizon of interpretation. In my reading of Honneth, it seems that this desire for symmetry is furthered or even elevated by the freedom that surrounds the heteronomous nature of identity. Shared societal values are only shared insofar as it enables a variety of identities to achieve self-realization with their varying needs for esteem. Notably, while asymmetry seems inimical in the possibility of social solidarity, it is the very nature of asymmetry that makes symmetry possible through shared desires for social integration and acceptance. This further fortifies the idea that any value that we want to insert or integrate into societal norms should be able to convince, be it through discourse, violence, or even active dissent, the already existing sphere of social normativity.

\section{CONSOLIDATING HONNETH'S RECOGNITION THEORY}

The structure of Honneth's work revolves around the formation of identities through the socialization process involved in both institutional and individual relations. To begin with, the initial sphere of love works as an initial sphere of receptivity wherein subjects interact openly to learn and recognize new identities (Honneth 1995, 100). In this sphere, subjects suspend existing barriers such as demands for legal and economic norms (Honneth 2014, 135 -136). This sphere figures itself in early familial 
relations encounters with new friends or simply a receptivity to strangers or new identities. The learning process begins as subjects open to differences to integrate both parties to asymmetrical differences. ${ }^{1}$ The situations wherein this sphere occurs are pervasive and transcend most restrictive barriers for encounters such as economic, psychological, sexual, and even racial factors are suspended due to the willingness of both parties to learn from each other's identities. In The Struggle for Recognition, Honneth refers to G.H. Mead's familial role of the sphere of love for integrating infants through their constant interactions with their caregivers (parents, kin, guardians, etc.) (Honneth 1995, 103). Infants are given a high degree of tolerance due to their lack of understanding of social norms; thus, caregivers, to a certain degree, suspend their normative expectations from infants to the degree that they allow infants to adopt and integrate to the normative expectations of their caregivers. In more recent work, Honneth provides an expansive understanding of the sphere of love in the context of friendship. Honneth, for example, refers to the role and progression of social clubs in Europe as an area of learning beyond the scope of infant integration and familial care (Honneth 2014, 136). Social clubs or pubs, for Honneth, gradually eliminated the restrictive structure of social classification by allowing individuals to mingle openly in an environment where receptivity takes place, and new norms are mutually learned through the relations of friendship. Moreover, the gradual erasure of class restrictive practices of social interactions also allowed men and women (or, if you prefer, men and men and women and women) to engage freely in intimate relations without the pressure of arranged marriages (Honneth 2014, 138). Tolerance in this sphere is met with the expectation of reproducing and negotiating norms within partners interaction; while there are some liberties as far as tolerance is concerned of difference or otherness is concerned, they are nonetheless looking at the goal of mutually recognizing each other despite their differences.

Asymmetries in identities provide a greater learning process for individuals in social interactions; not only do these relations provide an affirmation of one's identity, but they also provide alternative means of attaining self-realization. Social pathologies, or disintegrative forms of relations, are seen in this sphere in the form of disrespect through either abuse or physical violation (for example, torture or rape) (Honneth $1995,106 ; 129)$. This breaks the possibility of receptivity in so far as the integrative role of subjects is immediately exploited to take advantage of individuals seeking integration (for example, rape in the case of intimate relations, torture in the case of societal or communal relations, and abuse in the case of familial relations).

In the second sphere, the sphere of rights, Honneth $(1995,108)$ invokes the recognition of subjects that are integrated within society to invoke expectations of recognition through either law or custom that would allow individuals to self-actualize, producing what he would refer to as a view of the 'generalized other.' The sphere of love prepares individuals to recognize others insofar as they have been given the normative resource to form their identities and recognize other identities (either through familial relations, friends, or intimate relations). The sphere of rights, thus, invokes a mutual acknowledgment of subjects in their normative expectations of respect insofar as they can be an instrument of reproducing and enacting societal norms that integrates them into society (Honneth 1995, 109). The expected pathological 
outcomes coming from disintegrative practices in this sphere involve the denial of already existing rights or exclusion from a normative expectation that is already in place in social relations (Honneth 1995, 120-121). For example, denying one's right to dispose or utilize private property freely is a disintegrative social pathology; exclusions from common rights enjoyed by other members of society by racial or sexual discrimination, and unreasonable class privileges (for example, greater access to legal rights due to economic privileges).

The sphere of rights serves two functions in Honneth's social philosophy; it can be a resource to protect individuals from becoming objectified or denied proper recognition; moreover, it can also provide individuals with the necessary resources to seek self-actualization of identities. In the third sphere, the sphere of esteem, individuals gain recognition through their contribution to the pool of normative resources enjoyed in society (Honneth 1995, 122). By providing products and services that are reciprocally enjoyed by other members of society, individuals reciprocally gain affirmation through the recognition of their accomplishments. For example, a person working in a toilet factory, not only enjoys wages as compensation for his or her work but also contributes back to society by providing society with the toilets that they need for consumption. Moreover, the contribution of the subject to society replenishes the pool of normative resources if we consider taxation. Not only will those taxes serve the interest of the contributor, but they will also serve the interest of others who draw from the utilities and services offered by the government to its citizens. In Honneth's recognition theory, the sphere of esteem serves as a pinnacle of affirming identities and their inherent diversities. Different needs are fulfilled through different capacities of individuals to create varying products for society. Despite asymmetries of identities, individuals should find ways of convincing or negotiating their importance towards society through the products that they produce. It is in this sphere that we begin to understand that social relations are inherently reciprocal to the extent that altruism itself becomes a luxury. Moreover, the necessity of insisting on a reciprocal relation means that normative resources are not simply protected; they are essentially replenished. The experience of disrespect in this sphere is best exemplified by the monopoly and endangerment of the possibilities for self-realization and selfactualization; for example, the threat of replacing one's career or source of sustenance with either new technologies or cheaper outsourced labor. More so, it could also be felt in the experience of losing one's validation from society due to monopolies of possibilities (For example, not being selected for a job because you did not graduate from a specific school; not selected for government service because you don't know anyone within the government, etc.). This dynamic of disrespect means that on both sides, people that demand the right to be recognized, and people who are within the system of recognition requires reciprocal and mutual receptivity to their asymmetric needs (Honneth 1995, 127). For example, a migrant refuge might have the normative right to seek asylum in neighboring countries but may also need to make it a point to contribute back to their hosts. On the other hand, people from host countries might demand the right to preserve their way of life and culture but must also open up to the possibility that other forms of culture and mode of living may eventually benefit their existing enjoyment of normative resources. 
Following this need to re-adjust, re-align, and re-integrate, Honneth found it necessary to add another layer that would facilitate a feedback loop in the three spheres of recognition. The main problem that one would encounter in reading Honneth's work is the assumption that the sphere of love, rights, and esteem is linearly situated and fixed. This problem creates a misreading of Honneth's intention of enlarging the horizon of social struggles as an area of learning new ways of establishing social solidarity. Honneth's appropriation of Hegel's idea of the Sittlichkeit or the "ethical life" relies on the constant broadening of normative resources from within the experience of social struggles. Honneth's much-needed addendum happens in his lecture on Reification (2008), where he points out the necessity of antecedent recognition as an avenue to re-learn and re-evaluate existing norms (Honneth 2008, 59). Antecedent recognition is the reflective stance in which individuals look back at their previous relations and engagements to ponder whether one has in any way stepped on the precipice of disrespect (See Zurn 2015, 46). The role of this sphere is to continuously evaluate existing norms within the three spheres of recognition so that individuals can autonomously tweak their normative values and expectations.

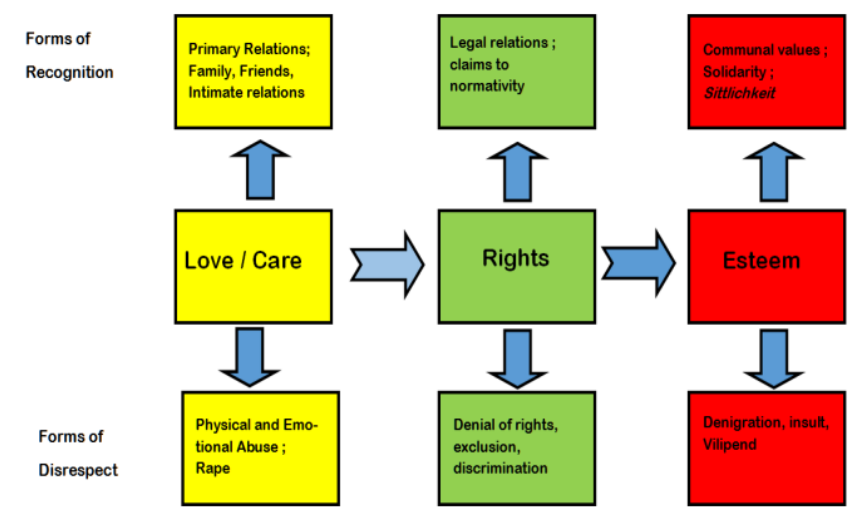

Fig.1 Initial Spheres of Recognition

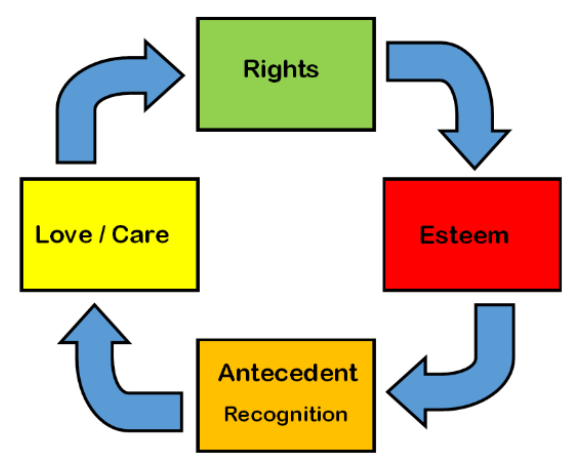

Fig.2 Antecedent Recognition 
The context of these initial three spheres of recognition takes place within the spheres of social interaction in personal relations, market economy, and democracy or political society. Appropriately, the sphere of love belongs to the sphere of personal relations, the sphere of rights, belong to the sphere of democracy or political society, and the sphere of esteem resides in the same area as the market economy. This further clarifies that the role that individuals play in society is not limited to just one context of the spheres of recognition. Moreover, the function of antecedent recognition means that there is always a sense of a feedback loop in these areas of interaction due to the inter-related nature of the spheres of social interaction.

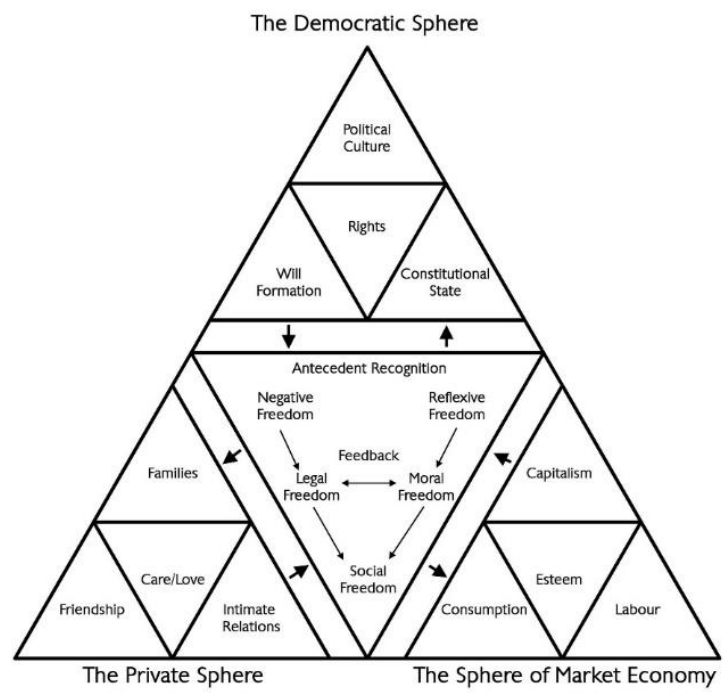

Fig. $3^{2}$ Convergence of the Spheres of Recognition and Spheres of Social Interaction

In Fig.3, the convergence of the spheres of recognition and the sphere of social interaction contextualizes the normative roles that an individual plays within society as he or she participates in the generation of normative resources that gives recognition to identities. In Freedom's Right, Honneth outlines the relationships that individuals have with each sphere of social interactions. While the connections between the spheres of recognition and the sphere of social interactions are somewhat obvious, merging these spheres provides a panoramic outlook of recognition and the role that they play in social interactions. In the sphere of care/love, the relations exhibited are contextualized under the sphere of private or personal relations. In as much as instances of care/love guides relationships through mutually desired demarcations (Honneth $1995,107)$, interactions that revolve around them take a private form of normativity, free from any form of calculations other than their immediate subjective sympathy and sentiment (Honneth 2014, 136). While the immediate family serves as the training ground for the child's externalization of a generalized other (Honneth 2014, 158), friendship also plays an important role in broadening the understanding of a 
generalized other (Honneth 2014, 137). Ultimately, the cycle in the private sphere of personal relations recurs in intimate relations as the individual meets another individual where they decide to create a family unit of their own (Honneth 2014, 143). In the case of esteem or solidarity, the experience of recognition in terms of honor or worth is generally felt in the process of acquiring affirmation from society (Honneth 1995, 124 - 25). Translating this into actual social interactions means that the individual in this sphere of recognition participates as a laborer, consumer, and capitalist in the market economy (Honneth 2014, 177). Thus, a laborer earns their esteem by having his or her work valued by society in the material form of compensation, which in turn allows the subject to consume products and services that would manifest their value in terms of attaining their forms of self-realization. A student, for example, that works in a job to pay for his university tuition fees will find validation in the fact that his work can pay for his tuition. A third role that individuals also play aside from labor and consumption is their possible role as capitalists or investors, who, in their shared goals and aspirations, can pool their resources to attain such goals and aspirations. Participants in the sphere of the market economy contribute to the goal of attaining the material resources necessary for each role; laborers create products and services for consumption, while capitalists undergird the necessary material and social infrastructure that allows the laborers and consumers to satisfy their projects of self-actualization. The recognition of rights, in the sphere of democracy, creates the necessary participative role of individuals in influencing the state in their legal rights (Honneth 2014, 253 -255), either through their constant fostering and formation of a political will, the reproduction of the constitution as its normative expectation, and contributing his or her own identity in the political culture.

\section{SOCIAL STRUGGLES AND THE REPLENISHMENT OF NORMATIVE RESOURCES: THE CONTEXT OF RECOGNITION}

The context of recognition takes place in societies that enable and reproduce social freedom. To be specific, Honneth explicitly refers to democratic societies in Freedom's Right. However, a wider scope of interpretation could open this context to societies that have to a certain degree, access to moral and legal freedom. Legal and moral freedom plays an important role in establishing autonomy in society. Legal freedom refers to the freedom of subjects to dispose of their resources as they please (Honneth 2014, 74) if they are within the validity of established normative practices. The purpose of this is to allow individuals to become selective with their intended possibilities for self-realization and self-actualization. For example, the legal capacity to dispense one's estate either as a domicile for personal use, leasing, or for purposes of business allows subjects to exercise a sense of autonomy that prevents them from merely confirming to dominant forms of self-actualization. This freedom extends further to options that are beyond the scope of property, such as the choice to seek different types of professions or practice certain types of faith. Moral freedom, on the other hand, is the capacity for subjects to self-legislate their internal sense of morality to guide both practices and expectations of individuals (Honneth 2014, 99). Having an autonomous sense of moral code means that subjects are not objectified into 
following existing established principles. In this sense, should subjects accept the moral principles of existing normative practices, they affirm them not because it is the only moral code in society, but rather because they freely accept prevailing moral principles.

Both legal and moral freedom implies a social infrastructure to guarantee their continuing existence and possibility. For Honneth (2014 p. 131), both legal and moral freedom are manifestations of social freedom. Social freedom is found within the context of the spheres of social interaction, namely personal relations, the market economy, and democratic or political society. These three spheres of social interaction guarantee social freedom by providing possibilities of self-actualization and realization, material sustenance, and socio-political participation. These spheres of social interaction are also co-dependent on each other, in as much as they are ought to mutually sustain each other with the resources that they provide. Each sphere also relies on the three roles that individuals play within this specific sphere of interaction. For example, a laborer is not merely providing labor for the market economy; he or she also takes the role of the consumer or investor.

In the sphere of personal relations, individuals form bonds through friendships, family, and intimate relations. These relations open learning possibilities of selfrealization and self-actualization through reciprocating receptivity to partners of social interaction. For example, one can learn varying career options through one's family, friends, and intimate relations, or one can learn possible avenues for understanding happiness or caring for oneself through these roles as a friend, family member, or as an intimate partner. In the sphere of market economy, one actualizes a possibility of self-realization in the function of the consumer, laborer, and investor/capitalist. The role that one takes is not merely limited to the function of providing labor; one also reciprocates through other laborers by consuming their products. To finance this, one goes as far as becoming an investor or capitalist to allow greater consolidation of resources to gain profit (this, of course, does not simply imply the function of large investors, it can also be realized in cooperatives, financial investments through stocks and bonds, and real estate). In the sphere of democracy or political society, the transformation and sustenance of norms are established through the roles that are played out by participants of this interaction. Individuals in this sphere of interaction play the role of shaping their own will through social interactions, participation in political discourse, which in turn leads to the sustenance and the support of a constitutional state. For Honneth, the participation of individuals in this sphere is necessary insofar as these roles allow individuals to legitimize their identities and convince society to recognize their concept of self-realization and self-actualization. These roles are co-dependent on each other, not only in the case of an individual but also for society. The moment that deficits in the capacity of these spheres to provide normative resources for each other (for example, the market economy cannot provide the proper material resources for familial relationships to function), the compensatory action of the other spheres of interaction creates pathological relations from the compensating sphere. One can then look at the convergence of the spheres of recognition and social interaction either as a reverse diagnosis (concerning deficits in 
the normative resources) or as a projective diagnosis (with possible surpluses that can be generated by a sphere of social interaction).

\section{SOCIAL PATHOLOGIES AND DEFICITS WITH NORMATIVE RESOURCES}

In the context of Honneth's recognition theory, social pathologies are seen in the increasing level of social atomization between individuals in the spheres of social interaction. By locating certain deficiencies in the spheres of social interaction, one can understand social pathologies as a consequence of compensating for lacking normative resources. For example, the common conception of a market economy as a sphere of interaction as an amoral sphere is only realized if the political or democratic sphere does not make the necessary measures to protect the interests of its three roles and participants. As Honneth $(2014,187)$ notes in Durkheim's work, the case of anomie is attributed to the instrumentalization of the participants solely for the interest of one party. For example, if investors/capitalists are given free rein on their desire for profitability, the laborers and consumers may suffer. Moreover, both laborers and consumers can also exploit these demands should the democratic/political institution fail to maintain reciprocal relationships within the sphere. Laborers can demand too much without giving back something in return and erode profitability from investors while at the same time demand increasing prices from the consumers. On the other hand, consumers can inflate their demand for goods and pay for such goods for less, which in turn will also alienate the laborer and the investors.

From the perspective of either of the spheres of social interaction, certain forms of a deficit in one of the spheres would mean that the other spheres must compensate just to hold on to certain spheres that are still functional. For example, deficits in the sphere of democracy and market economy usually turn the sphere of personal relations as a prime motivation for justifying all sorts of crime in the name of survival. In this case, the lack of support from the government and the lack of possibilities to which individuals can self-actualize leads to criminal activity that is mostly justified by familial needs or needs from intimate relations.

\section{AN OUTLOOK TOWARDS SOCIAL SOLIDARITY}

Honneth's critical theory offers a robust and sustainable analysis of understanding social asymmetries as a possibility for enriching normative practices and expectations. What Honneth demonstrates is that diversity, if it provides a reciprocal value to society, can give rise to an autonomous and cohesive society. Moreover, we can also see that identities are not ought to be seen as purely differentiated from existing norms but rather are products of selectivity of existing norms. This is to say that despite the current trend of valorizing identities and infinite responsibilities to subjects demanding recognition, identities cannot have the quality of having an absolute difference enough to challenge existing norms or prevent demands for reciprocity. In other words, others are not "absolutely" other to me, to you, or anyone, to the extent that their normative claims are always rooted in already existing norms. 
Even in the light of their asymmetric needs for recognition, the socialized nature of their identity formation means that no identity is alien to any socialized subject. This means that subjectivities, despite their asymmetrical needs, will find ways of integrating themselves into the spheres of social interaction, not only in the manner of conforming to the norms, but rather, in the manner where they can participate in the formation and reproduction of norms. Social movements that struggle for recognition means that parties involved in such a struggle (be it in the perspective of the claimant or the recognizer) will have to engage each other's conflicting motives for selfrealization and self-actualization while finding common grounds to cooperate and reciprocate through each other's needs. That is why in the context of recognition, Honneth will insist (much to the dismay of Paul Ricoeur) that reciprocity goes hand in hand with freedom and autonomy.

The practical aspect of Honneth's recognition theory lies precisely in the way he derives his content of critique from already existing normative practices. This means that the force of critique does not come from the outside, nor does it invoke transcendental or imaginary sources of norms, ethics, or morality. To add to this feature, Honneth's theoretical method of explaining political philosophy through social philosophy eliminates the need for "noble lies" that obscure the intentions and goals of political philosophy for a grand order of society. Thus, discourses regarding the role of rationality in social philosophy not only find their historical basis in the experience of subjects struggling for recognition, but they also find material content in the complex development of subjectivity from the process of socialization. This sets Honneth's theoretical perspective above and beyond his mentor and predecessor, Jürgen Habermas since the force of reason is not merely explained in the normativity of linguistic practices; it is also made more meaningful in the context of everyday practices of social interactions.

\section{NOTES}

1. In The Struggle for Recognition, Honneth demonstrates this through the initial separation of the mother and the child as the mother begins to gradually introduce to the child her own 'needs' (Honneth 1995, 100). Not only does this phase introduce the child to the idea of differences in identities, it also creates the necessity for understanding the need of the mother to become a reciprocal partner in the process of recognition. This will later become instrumental in a person's understanding of social relations as a reciprocal process where he or she will encounter other subjects either as friends, family members, or intimate relations.

2. See Pada 2017, 164.

\section{REFERENCES}

Bolaños, Paolo. 2016. Between struggle and peaceful dialogue: An overture to Honneth and Ricoeur on recognition. Budhi: A Journal of Ideas and Culture. Vol.20, No.2: 85-117. 
Honneth, Axel. 2014. Freedom's right: The social foundation of democracy. Translated by Joseph Ganahl. Cambridge: Polity Press.

Honneth, Axel. 2008. Reification: A new look at an old idea. Translated by Joseph Ganahl. New York: Oxford University Press.

Honneth, Axel. 2014. The normativity of ethical life. Philosophy and Social Criticism. Sage, Vol.40, No. 8: 817-826.

Honneth, Axel. 1995. The struggle for recognition: The moral grammar of social conflicts. Translated by Joel Anderson. Cambridge: Polity Press.

Kuhn, Thomas. 1962. The structure of scientific revolutions. Chicago: The University of Chicago Press.

Marcelo, Gonçalo. 2013. Recognition and critical theory today: An interview with Axel Honneth. Philosophy and Social Criticism. Sage, Vol.39, No.2: 209-221.

Pada, Roland Theuas DS. 2017. Axel Honneth's social philosophy of recognition. Newcastle upon Tyne: Cambridge Scholars Publishing.

Plato. 2003. The republic. Translated by Tom Griffith. Cambridge: Cambridge University Press.

Ricoeur, Paul. 2005. The course of recognition. Translated by David Pellauer. London: Harvard University Press.

Sowell, Thomas. 2011. Grasshopper and ant. In The Thomas Sowell reader. New York: Basic Books, 11-13.

Sowell, Thomas. 1999. The quest for cosmic justice. New York: Touchstone, Rockefeller Center.

Swift, Jonathan. 2008. A modest proposal and other short pieces. Pennsylvania: Penn State electronic Classics Series.

Wyklicky Helmut and Skopec Manfred. 1983. Ignaz Philipp Semmelweis, the Prophet of Bacteriology. In Infection Control. Vol.4 No.5: 367-370. 10.1017/s0195941700059762 Please indicate pages

Zurn, Christopher. 2015. Axel Honneth: A critical theory of the social. Cambridge: Polity Press. 